\title{
The safety benefits added by lateral roadside clearance to urban streets
}

\author{
T. H. Maze, C. Sax \& N. R. Hawkins \\ Center for Transportation Research and Education, \\ Iowa State University, USA
}

\begin{abstract}
The distance from the edge of the roadway to a fixed object is known as the clear zone, or lateral offset. Clear zones provide a buffer space between the roadway and adjacent fixed objects. In the U.S., guidance for clear zones was first promulgated in the $1960 \mathrm{~s}$, and over time has been updated by the American Association of State Highway and Transportation Officials (AASHTO), which produced its most recent Roadside Design Guide in 2006. AASHTO clear zone guidance, however, is focused on rural roadway conditions as opposed to urban (curbed roadways) where AASHTO simply recommends a minimum clear zone distance of 18 inches (45.7 centimeters). Some jurisdictions have adopted this minimum urban clear zone standard of 18 inches while others have developed more stringent requirements.

This paper provides guidance in developing realistic clear zone setback distances through a crash and clear zone analysis on Iowa curbed roadways. The analysis showed that fixed object crashes were disproportionately more hazardous than other types of urban crashes. Clear zone setbacks were contrasted to safety performance on 13 corridors within two Iowa communities. The analysis found that roughly 90 percent of all fixed object crashes occurred within a clear zone distance of 5 feet ( 1.5 meters). The same data were used to show that roughly 90 percent of the crash costs (economic loss) were within a clear zone distance of 3 feet ( 1 meter). As a result of this research, the Iowa Department of Transportation is considering changes to their urban clear zone policies.
\end{abstract}

Keywords: urban street clear zone, lateral offset, roadside safety. 


\section{Introduction}

The distance from the edge of the roadway to a fixed object is known as the clear zone, or lateral offset. Clear zones provide a buffer space between the roadway and adjacent fixed objects, as illustrated in Figure 1.

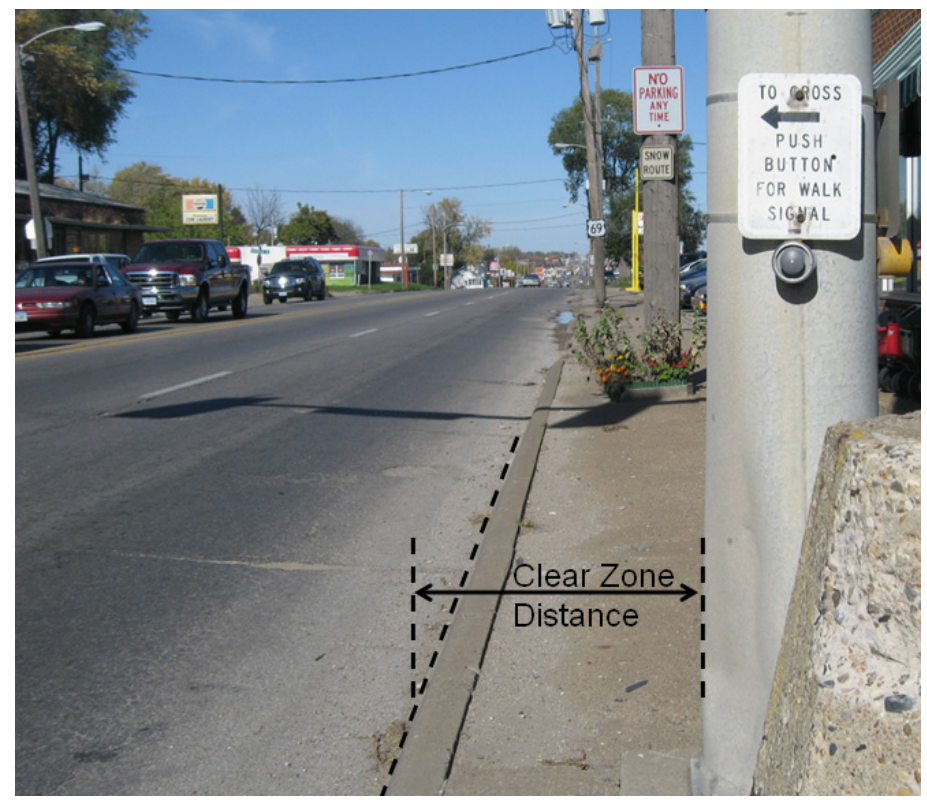

Figure 1: $\quad$ Illustration of clear zone distance.

In the United States of America (USA), clear zone standards were not established by federal standards or guidance until the 1960s when the American Associate of State Highway and Transportation Official (AASHTO) promulgated design guidance through the Roadside Design Guide (latest revision is 2006) [1]. Prior to the creation of national guidance, jurisdictions (typically states) developed their own standards for clear zones, including urban streets. States continued to carry forward their standards for urban streets, making a patchwork of standards across the country. The AASHTO "A Policy on Geometric Design of Highways and Street" (The Green Book) established guidance of minimum lateral offset of 18 inches (45.7 centimeters) from the face of the curb to the first fixed object. Many states have adopted this as a minimum requirement, but on the other extreme, some states did not recognize the curb as a barrier, and required the designer to follow the roadside design guide (the offset could potentially be as much as 30 feet (approximately 9 meters)) [2].

Most states recognized that 18 inches was not enough distance for vehicles departing the roadway to recover and return to the driving lane without striking an object. As a result greater clear zone distances have been adopted in a non- 
uniform manner across the U.S. Most agencies have a process for approving exceptions to meeting minimum clear zone setbacks on a project specific basis.

\section{Background}

Within the urban setting, minimum clear zone distances, on curbed roadways, are controlled according to the policy of the roadway agency (e.g. primary Department of Transportation controlled roadway running through a local community). Minimum distances also vary significantly between similar organizations and across the U.S. A few states, including Iowa, choose to set ten feet (about 3 meters) of lateral offset as a standard. Although it is not entirely clear where this standard came from, it is believed to have been influenced by a 1989 study by Turner and Barnett which first identified the ten foot distance [3]. They preformed case studies for approximately 350 isolated urban utility poles and investigated the crash history of these poles. About 90 percent of all utility pole crashes took place when the poles were 10 feet or less from the edge of the roadway. The study did not take into account relative location of other fixed objects, or the presence of such features as parking or turning lanes, or even curbs. As a result, it is believed that several jurisdictions adopted this as a standard without considering the assumptions made in the study.

\subsection{The problem}

It is clear that the lateral offsets provided by clear zone minimums add a safety benefit for most motorists by making it less likely for them to crash into a fixed object, but it is unclear how much benefit is provided by each increment of additional lateral offset. Therefore, the street designer is left with the dilemma of knowing the exact cost of moving back a fixed object, but not the resulting safety benefits. For example, in Figure 2, a typical urban intersection of two four-lane streets with no auxiliary turning lanes is shown. The picture is taken parallel to an urban street which is a state highway; therefore, the state government would like any improvements to this intersection to include a lateral offset of ten feet. The existing intersection was built before the ten foot requirement, and thus meets the standards at the time of the design.

This intersection has a significant turning movement with no left turn lanes. This leads to right-angle and rear-end collisions when left turning drivers stop in the through lane to make a left-turn. Although the safety of the intersection could be significantly improved by building auxiliary left-turn lanes, the space needed for the lanes, plus the ten foot lateral offset will require that all utility poles and other fixed objects be moved back. This action would significantly impact adjacent parking, signage, and property screening/green space areas. Acquiring the necessary right-of-way is a major expense but as is typically the case, the owners of these businesses believe, and may be correct, that the project impact will create such a hardship as to ruin the vitality of the property and are requiring significant compensation. Therefore, the designer can estimate the cost of meeting the ten foot setback requirement but has little information to contrast 
these costs with incremental safety benefits. As often happens, meeting the lateral offset requirement becomes so expensive and politically controversial that the safety project is postponed and crashes which could be avoided with auxiliary lanes continue.

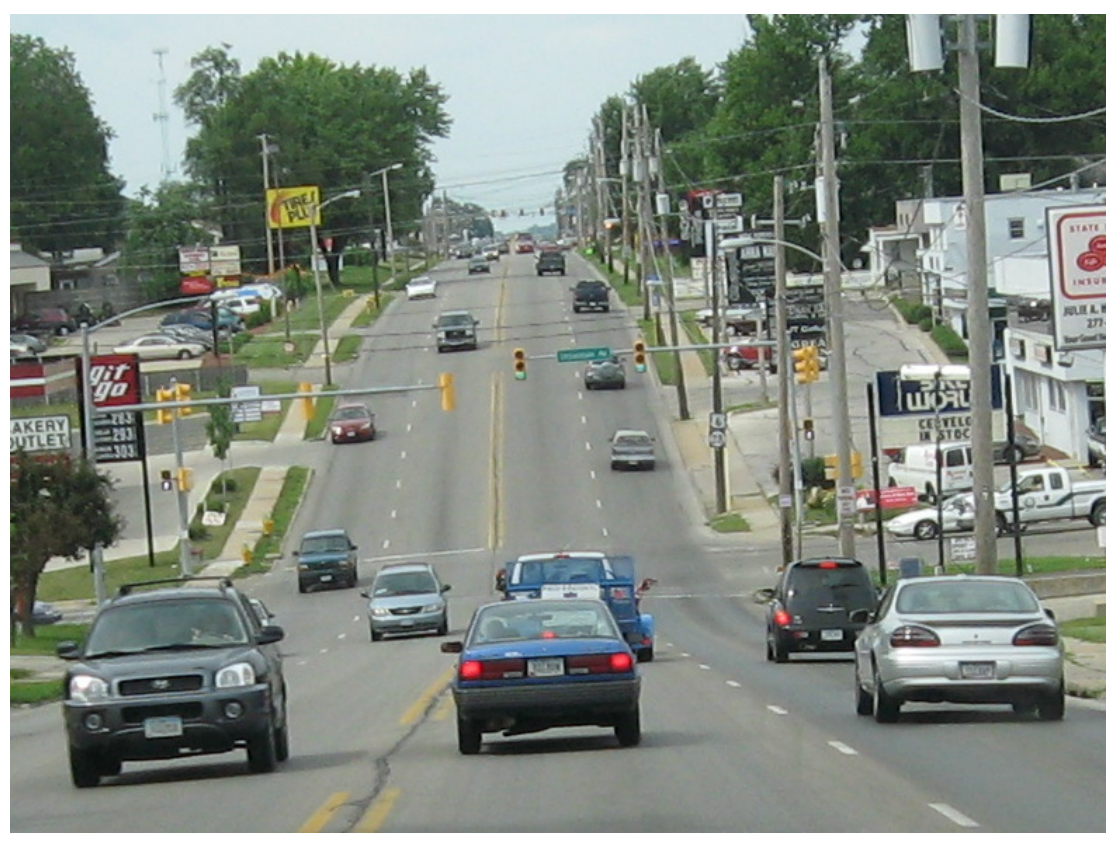

Figure 2: Illustration of a challenging intersection for a clear zone.

In a review of urban crashes in Iowa, three years of crash data were aggregated and about three percent of all crashes were found to be urban fixed object crashes (Iowa is largely rural) [4]. Six percent of all urban crashes were found to be with fixed objects on curbed streets, fifteen percent of all the fatalities in urban area were found to be crashes with fixed objects on curbed streets. These findings indicate that fixed object crashes are far more serious than other types of urban crashes, and highlight the need to reduce or minimize fixed object collisions.

\section{Research approach}

To understand the cost and frequency of fixed object crashes along urban streets, field data were collected along eleven corridors within Des Moines and two within Waterloo, Iowa. For each corridor, field data were gathered regarding the distance from the face of the curb to each fixed object using a handheld computer, a laser distance measuring device, and a global positioning system (GPS). 
Most of the streets had speed limits varying from twenty-five to thirty-five miles per hour (40 to $56 \mathrm{kph}$ ). Each fixed object was identified by type and the data were correlated to crashes using a GIS environment. The crashes could not be linked directly to a specific fixed object crash because of minor crash location inaccuracies. However, the analysis could determine the lateral offset of fixed objects and other descriptive statistics (minimum distance to the first fix object, maximum distance to a fixed object, and average distance to a fixed object over a linear distance, for example over the length of a block).

The corridors were broken into 15 meter lengths, blocks, and segments. Segments were a series of blocks with similar land use, traffic volumes, roadway geometry, and traffic volumes. The segment limits were a matter of interpretation of the analyst; however, they worked best at identifying relationships. This is because crashes with a fixed object are a relatively rare events, and segments (multiple blocks) had enough fixed object crashes to draw relationships. There were a total of forty-three segments defined in the thirteen corridors.

\subsection{Analysis}

Estimation of a safety performance function by corridor was attempted, but no strong statistical relationships were found. Instead, the methodology used by Turner and Barnett was applied to the field and associated crash data collected. The cumulative percentage of fixed object crashes was plotted against the offset to the closest fixed object in the segment. As seen in Figure 3, ninety percent of all fixed object crashes occurred when the lateral offset to the first object is about five feet (1.5 meters).

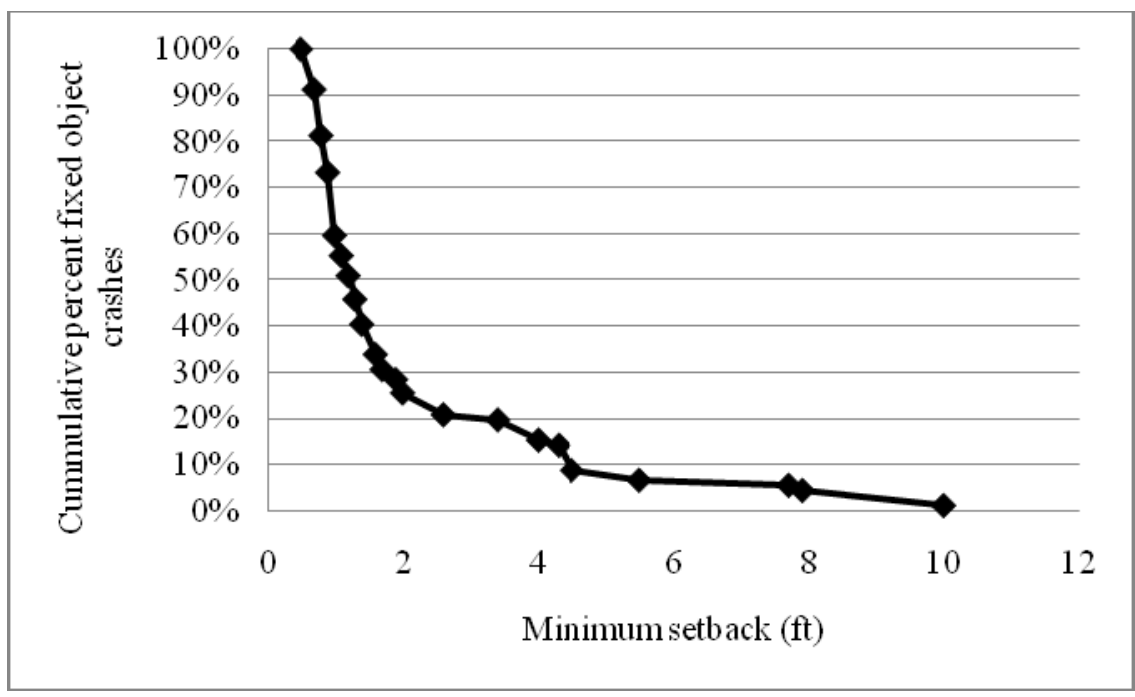

Figure 3: $\quad$ Minimum setback contrasted with crashes. 
This matches conventional thought. That is, if an errant vehicle is going to deviate back into the travel lane, it will do so shortly after mounting the curb and the objects that are most likely to be hit are those closest to curb.

Figure 4 shows the result of an additional analysis, based upon the same data, but contrasting the cumulative economic loss of a crash, by severity, with minimum object setback by segment. The Iowa Department of Transportation estimates the economic loss per crash type as $\$ 3.5$ million for a fatal crash down to $\$ 2,700$ for a property damage only crash. Figure 4 shows that about ninety percent of the crash costs fell within a minimum fixed object offset of three feet or less (almost a meter). This again agrees with intuition as the most severe and most frequent crashes are believed to be with fixed objects adjacent the roadway.

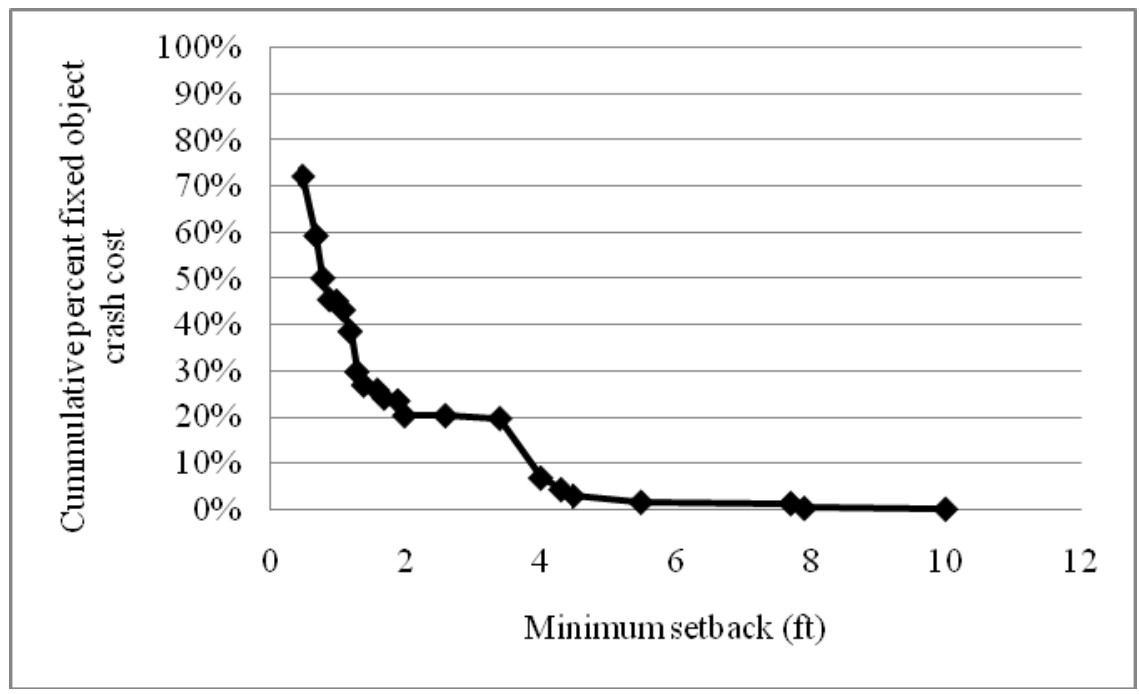

Figure 4: $\quad$ Minimum setback contrasted with crash costs.

\section{Conclusion}

This research illustrates that, within an urban setting and on curbed roadways of similar conditions, a minimum clear zone setback distance of ten feet is probably unnecessary. The data also show that, in contrast to the AASHTO 1.5 foot clear zone guidance, a five foot clear zone distance is more realistic. It was also found that most fix object crashes take place at the intersections, meaning that addition offset should be considered within the area of influence of an intersection.

As a result of this study, the Iowa Department of Transportation is examining a change in lateral offset policy on curbed streets. Additional research is needed to expand and support the above findings. These finding do not apply to on highspeed urban streets (45 mph or $70 \mathrm{kph}$ or higher) as additional research efforts are needed to review clear zone impacts under these conditions. 


\section{References}

[1] AASHTO. 2006. Roadside Design Guide. Washington, DC: American Association of State Highway and Transportation Officials, 2006

[2] AASHTO. 2004. A Policy on Geometric Design of Highways and Streets (The Green Book). Washington, DC: American Association of State Highway and Transportation Officials, 2004.

[3] Turner, D.S. and T. Barnett. "Case Study: Poles in the Urban Clear Zone." Transportation Research Record Number 1233, pp. 155-163, Washington, D.C., 1989.

[4] Maze, T.H., C. Sax, and N.R. Hawkins, "Clear Zones - A Synthesis of Practice and an Evaluation of the Benefits of Meeting the 10-ft Clear Zone Goal for Urban Street," Report Prepared by the Center for Transportation Research, Iowa State University, Ames, IA, 2008. 